\title{
Mechanism of sperm capacitation and the acrosome reaction: role of protein kinases
}

\author{
Debby Ickowicz, Maya Finkelstein and Haim Breitbart
}

Mammalian sperm must undergo a series of biochemical and physiological modifications, collectively called capacitation, in the female reproductive tract prior to the acrosome reaction (AR). The mechanisms of these modifications are not well characterized though protein kinases were shown to be involved in the regulation of intracellular $\mathrm{Ca}^{2+}$ during both capacitation and the AR. In the present review, we summarize some of the signaling events that are involved in capacitation. During the capacitation process, phosphatidyl-inositol-3-kinase (PI3K) is phosphorylated/activated via a protein kinase A (PKA)-dependent cascade, and downregulated by protein kinase $\mathrm{C}_{\alpha}$ (PKC $\alpha$ ). PKC $\alpha$ is active at the beginning of capacitation, resulting in PI3K inactivation. During capacitation, PKC $\alpha$ as well as PP $1 \gamma 2$ is degraded by a PKA-dependent mechanism, allowing the activation of PI3K. The activation of PKA during capacitation depends mainly on cyclic adenosine monophosphate (cAMP) produced by the bicarbonate-dependent soluble adenylyl cyclase. This activation of PKA leads to an increase in actin polymerization, an essential process for the development of hyperactivated motility, which is necessary for successful fertilization. Actin polymerization is mediated by PIP $_{2}$ in two ways: first, PIP $_{2}$ acts as a cofactor for phospholipase D (PLD) activation, and second, as a molecule that binds and inhibits actin-severing proteins such as gelsolin. Tyrosine phosphorylation of gelsolin during capacitation by Src family kinase (SFK) is also important for its inactivation. Prior to the AR, gelsolin is released from $\mathrm{PIP}_{2}$ and undergoes dephosphorylation/activation, resulting in fast $\mathrm{F}$-actin depolymerization, leading to the AR.

Asian Journal of Andrology (2012) 14, 816-821; doi:10.1038/aja.2012.81; published online 24 September 2012

Keywords: sperm capacitation; acrosome reaction; AR; PKC $\alpha$; PI3K; PKA; gelsolin; PIP 2

\section{INTRODUCTION}

Ejaculated mammalian spermatozoa should reside in the female genital tract for several hours before gaining the ability to fertilize the egg. In humans however, sperm must move out of the seminal plasma immediately after ejaculation and appear in the fallopian tube within minutes. As soon as sperm are moving out of the ejaculate and passing the cervical mucus, they undergo several biochemical changes collectively called capacitation, ${ }^{1,2}$ which was first independently reported nearly six decades ago by Austin ${ }^{3}$ and Chang. ${ }^{4}$ These changes involve molecules absorbing on, or integrating into, the sperm plasma membrane during epididymal maturation. The removal or alteration of these molecules prepares the sperm toward successful binding to the egg and fertilization.

During mammalian fertilization, the capacitated spermatozoon penetrates the cumulus oophrous of the ovum, and then binds to the zona pellucida $(\mathrm{ZP})$ with its plasma membrane intact. After binding to the egg $\mathrm{ZP}$, the spermatozoon undergoes an exocytotic process called the acrosome reaction (AR). ${ }^{5-8}$ This event is required for fertilization, because it enables passage of the spermatozoon through the $\mathrm{ZP}$ and its subsequent fusion with the egg oolema.

Capacitation includes multiple physiological and biochemical modifications. ${ }^{5}$ The biochemical changes associated with the capacitation process include an efflux of cholesterol from the plasma membrane leading to an increase in membrane fluidity and permeability to bicarbonate and calcium ions, hyperpolarization of the plasma membrane, ${ }^{9}$ changes in protein phosphorylation and protein kinase activity ${ }^{10-12}$ and increases in bicarbonate $\left(\mathrm{HCO}_{3}{ }^{-}\right)$concentration and intracellular $\mathrm{pH}, \mathrm{Ca}^{2+}$ and cyclic adenosine monophosphate (cAMP) levels.

Capacitation can be divided into two signaling events: fast and slow. ${ }^{11}$ These events take place during the passage of sperm within the female reproductive tract. The fast events include activation of the vigorous and asymmetric movement of the flagella and these happen as soon as the sperm leave the epididymis. The slow events include changes in the pattern of movement (hyperactivation). Protein tyrosine phosphorylation is another landmark of capacitation but occurs during the late stages of capacitation on a different timescale from cAMP/protein kinase A (PKA) activation. The fast event depends on PKA activation mediated by the $\mathrm{Ca}^{2+}$ and $\mathrm{HCO}_{3}{ }^{-}$-dependent soluble adenylyl cyclase. It has been suggested that $\mathrm{Ca}^{2+}$ is transported into the cell by the sperm-specific $\mathrm{Ca}^{2+}$ channel (CatSper) and $\mathrm{HCO}_{3}{ }^{-}$by the $\mathrm{Na}^{+} / \mathrm{HCO}_{3}{ }^{-}$cotransporter. ${ }^{11}$ The beginning of the slow events of capacitation is marked by the removal of cholesterol from the membrane by bovine serum albumin and the increase in its fluidity. ${ }^{11}$

Eventually, all these changes will lead to the capacitation of the sperm and as a final point, the following events occur: the ability to carry out the AR induced by biological agonist, $\mathrm{ZP}$, or progesterone; 
the ability to produce hyperactivation motility (HAM); exhibition of chemotactic behavior; ${ }^{13}$ and the ability to fertilize an oocyte.

\section{PROTEIN TYROSINE PHOSPHORYLATION}

Phosphorylation of proteins is a posttranslational modification event that acts as one of the cell's key regulatory mechanisms to control various cellular processes. ${ }^{14,15}$ Although both serine/threonine phosphorylation and tyrosine phosphorylation of proteins have been reported in spermatozoa, the tyrosine phosphorylation of a number of protein substrates has been associated with capacitation in the spermatozoa of most mammalian species, and is considered a hallmark event of capacitation. ${ }^{16-21}$

Several tyrosine phosphoproteins in capacitated buffalo and cattle spermatozoa were identified using 2D immunoblotting and mass spectrometry. These include serine/threonine-protein phosphatase PP1 22 catalytic subunit, the MGC157332 protein, alpha-enolase, 3oxoacid CoA transferase 2 and actin-like protein 7A. ${ }^{22}$

In human sperm, the identified Tyr-phosphorylated proteins include ion channels, metabolic enzymes and structural proteins (16), CABYR, a calcium-binding protein localized in the principal piece of the tail in association with the fibrous sheath ${ }^{23}$ and members of the extracellular signal-regulated kinase family. ${ }^{24,25}$ The main Tyr-phosphorylated structural proteins of the fibrous sheath ${ }^{16}$ are the family of A-kinaseanchoring proteins and their involvement in motility has been defined. ${ }^{26}$

In order to get a successful capacitation, several molecules are required; these include $\mathrm{HCO}_{3}{ }^{-}$, serum albumin and $\mathrm{Ca}^{2+}$. The $\mathrm{HCO}_{3}{ }^{-}$enters the sperm through the cotransporter $\mathrm{Na}^{+} / \mathrm{HCO}_{3}{ }^{-27}$ Physiological levels of $\mathrm{HCO}_{3}{ }^{-}$produce a rapid collapse of the asymmetry of the sperm plasma membrane attributable to the activation of enzymes that translocate membrane phospholipids, such as phosphatidylserine and phosphatidylethanolamine ${ }^{28}$ increasing the availability of cholesterol to external acceptors. ${ }^{11,13}$ This increase in the $\mathrm{HCO}_{3}{ }^{-}$ concentration also produces an increase in the intracellular $\mathrm{pH}$ and the activation of a unique type of adenylyl cyclase present in the sperm, the soluble adenylyl cyclase which results in increased levels of cAMP and cAMP-dependent PKA activation. The activation of PKA modulates the response of calcium channels such as CatSper, which produces changes in the membrane potential ${ }^{29}$ and increases in the intracellular $\mathrm{Ca}^{2+}$ concentration. PKA phosphorylates several proteins on Ser and Thr residues, activating, either directly or indirectly, several protein kinases and/or inhibiting protein phosphatases, which will finally produce an increase in the phosphorylation of Tyr residues. ${ }^{30-34}$

It has been shown that PKA inhibition blocks the onset of tyrosine phosphorylation. ${ }^{20}$ However, it was recently suggested that the Src family tyrosine kinases (SFKs) mediate the increase in tyrosine phosphorylation in mouse, human and bovine sperm. ${ }^{35-40}$

In murine sperm, PKA coimmunoprecipitates with Src, and this interaction leads to Src phosphorylation. ${ }^{41}$ It was shown that the Src kinase family inhibitor, SU6656 inhibits PKA phosphorylation, sperm motility, and in vitro fertilization, ${ }^{34}$ suggesting that two parallel pathways regulate phosphorylation events leading to capacitation: one requires activation of PKA, and the other requires inactivation of ser/thr phosphatases.

PKA phosphorylates various target proteins that are presumed to initiate several signaling pathways. In sperm exposed to $\mathrm{HCO}_{3}{ }^{-}$, cAMP rises to its maximum levels within $60 \mathrm{~s}$, and the increase in PKA-dependent phosphorylation begins within $90 \mathrm{s.}{ }^{13}$ This increase in tyrosine phosphorylation is a late event, which depends on the presence of albumin, $\mathrm{Ca}^{2+}$ and $\mathrm{HCO}_{3}{ }^{-}$in the capacitation medium, and correlates with capacitation. ${ }^{13}$ Inhibitors of PKA block sperm capacitation and the associated increase in protein tyrosine phosphorylation. ${ }^{42}$
Whatever the role of Tyr phosphorylation in capacitation, the level of Tyr phosphorylation in human sperm correlates strongly with the sperm-zona-binding capacity ${ }^{43}$ and alterations in Tyr phosphorylation have been found in subfertile subjects ${ }^{44}$ indicating its physiological role in fertilization.

\section{PROTEIN KINASES A AND C}

Mice that lack the unique sperm PKA catalytic subunit $\mathrm{C} \alpha 2$ are infertile despite normal mating behavior, and their sperm exhibits defects which are seen in both early and late capacitation-associated events. ${ }^{45}$ Results from mice lacking the atypical $\mathrm{HCO}_{3}{ }^{-}$-dependent adenylyl cyclase ${ }^{46,47}$ have conclusively demonstrated that an $\mathrm{HCO}_{3}{ }^{-}$-dependent modulation of the CAMP/PKA pathway is involved in the regulation of both fast and slow capacitation-associated processes.

It is well known that PKA is involved in regulation of sperm motility. Activation of the PKA catalytic subunit increases flagellar beat frequency during capacitation. ${ }^{48}$ In fact, PKA plays at least two independent roles in the regulation of sperm motility: a 'fast' action is required for the activation of flagellar beat, and a 'slow' action, such as the change in the flagellum waveform symmetry, requires PKA to be active for an extended time period. We recently showed that PKA mediates light-induced hyperactivated motility (HAM) in human sperm. ${ }^{49}$ It is currently accepted that capacitated sperm represents HAM. During the capacitation process, sperm change their motility pattern from progressive to HAM. ${ }^{50,51}$ HAM is a movement pattern characterized by asymmetrical flagellar beating observed in spermatozoa at the site and time of fertilization in mammals, ${ }^{52-55}$ and may be critical to fertilization success. ${ }^{56}$ It was shown that hyperactivated sperm penetrate the $\mathrm{ZP}$ much more effectively than non-hyperactivated sperm. ${ }^{57}$ If HAM is prevented, fertilization cannot occur. ${ }^{58}$

The presence of protein kinase $\mathrm{C}(\mathrm{PKC})$ in human, ${ }^{59} \mathrm{ram}^{60}$ and bovine $^{61}$ sperm was identified years ago. Functional studies also suggest the involvement of $\mathrm{PKC}$ in flagellar motility and $\mathrm{AR} .{ }^{62} \mathrm{PKC}$ exists in 11 isotypes, several of which can be simultaneously present in a single cell. There are three broad categories of PKC based on their requirements for activity, and the structure of their regulatory domains at the $\mathrm{NH}_{2}$ terminus. ${ }^{63}$ First, the conventional PKCs, namely $\mathrm{PKC} \alpha, \beta \mathrm{I}, \beta \mathrm{II}$ and $\gamma$ are dependent on diacylglycerol (DAG), phospholipids and calcium, with their regulatory domains containing a $\mathrm{C} 1$ domain, which binds DAG/PMA, and a C2 domain that binds anionic phospholipids in a calcium-dependent manner. Second, the novel PKCs are DAG and phospholipid-dependent, but are calciumindependent, and include $\operatorname{PKC} \delta, \varepsilon, \mu, \eta$ and $\theta$; their regulatory domains contain two $\mathrm{C} 1$ and one $\mathrm{C} 2$ domains, with the $\mathrm{C} 2$ domains lacking the calcium-coordinating acidic residues. The third category is that of the atypical PKCs, which are DAG and calcium-independent and include $\mathrm{PKC} \zeta$ and human $\mathrm{PKCl} /$ mouse $\mathrm{PKC} \lambda$; their regulatory domains lack the calcium-sensitive $\mathrm{C} 2$ domain and contain an atypical $\mathrm{C} 1$ domain that binds $\mathrm{PIP}_{2}$ or ceramide. ${ }^{64} \mathrm{PKC}$ s play a pivotal role in cell signaling, as a serine/threonine kinase, in particular for $\mathrm{Ca}^{2+}$-mobilizing ligands. ${ }^{65,66}$ This multi-isoenzyme family is involved in synaptic transmission, memory, learning, cellular growth, differentiation, transformation, metabolism, contraction, regulation of ion channel activity, exocytosis and gene expression. The PKC activators are produced by the various phospholipases. Enhanced phosphoinositide turnover provides $\mathrm{Ca}^{2+}$ and DAG via activation of phospholipase C (PLC).

The AR requires free extracellular calcium; ${ }^{67,68}$ however, activation of $\mathrm{PKC}$ induces the $\mathrm{AR}$ in a calcium-independent fashion. ${ }^{69} \mathrm{~A}$ calcium-dependent isotype of PLC $\gamma$ is activated during sperm capacitation, ${ }^{70}$ leading to activation of a broad range of PKC isotypes at the 
time of capacitation. ${ }^{8}$ Activation of sperm PKA leads to inhibition of PKC, probably via PLC inhibition. ${ }^{71}$

PKA activates a voltage-dependent $\mathrm{Ca}^{2+}$ channel in the outer acrosomal membrane that releases $\mathrm{Ca}^{2+}$ from the interior of the acrosome to the cytosol. ${ }^{72}$ The rise in $\mathrm{Ca}^{2+}$ levels might support PLC activation, followed by formation of $\mathrm{IP}_{3}$ which further elevate $\mathrm{Ca}^{2+}$ levels by mobilizing an acrosomal $\mathrm{Ca}^{2+}$ pool, and the formation of DAG, which activates specific PKC isoforms. The sperm plasma membrane contains a $\mathrm{Ca}^{2+}$ channel that is activated by PKC. ${ }^{72,73}$

Inhibitors of PKC block motility, while application of a crude PKC agonist increases motility. Studies on human sperm ${ }^{69}$ demonstrated that the crude PKC agonist could also induce the AR in the absence of an elevation of intracellular-free calcium as long as the sperm had previously undergone capacitation.

The large number of PKC isotypes, and the expression of most of them in sperm or eggs, suggest that this family of kinases has multiple tasks during gametogenesis, fertilization and early development. Differential regulation of the individual members of this kinase family can occur in three ways. The first is by means of the different cofactor requirements of the three categories of PKC. A second mechanism is the differing substrate specificities of the individual family members. Finally, individual kinases may be regulated by localization or enrichment of the specific isotype at specific locations in the sperm or egg. All these three mechanisms seem to have a role in fine-tuning the function of the kinase. ${ }^{63} \mathrm{PKC}$ was found to be localized mainly in the equatorial segment of the human sperm. ${ }^{59,74}$ In bull sperm, PKC is concentrated mainly in the postacrosomal and upper region of the acrosome. ${ }^{61}$ Activation of PKC is associated with translocation of the enzyme from the cytosol to the membrane fraction. Indeed, PKC translocates to sperm plasma membrane after treatment with phorbol ester. ${ }^{75}$ Recently, we showed that PKC $\alpha$ undergoes degradation and dephosphorylation during capacitation. ${ }^{76}$ This downregulation of PKC $\alpha$ occurs at the same time as the phosphorylation of Tyr467 on phosphatidyl-inositol-3-kinase (PI3K) regulatory subunit $\mathrm{p} 85$ is increased.

\section{PI3K}

PI3K is primarily responsible for the production of phosphatidylinositol-3,4,5-triphosphate $\left(\mathrm{PIP}_{3}\right)$ in response to growth factors. ${ }^{77}$ This enzyme is implicated in many biological processes, including cell survival, cell growth, cell movement and adhesion, protein synthesis, and cytoskeletal rearrangements. A role for PI3K has been suggested in sperm functions during capacitation and the AR. ${ }^{38,78,79}$ PI3K catalytic and regulatory subunits are present in sperm. ${ }^{79}$

It was shown that the PI3K inhibitor, wortmannin $\left(10 \mathrm{nmol}^{-1}\right)$, decreases $\mathrm{PIP}_{3}$ production in bovine sperm. ${ }^{38}$ We suggest that PI3K activity during capacitation is activated by PKA and inhibited by PKC $\alpha .{ }^{38}$ Inhibition of PKA by H89 blocks the elevation of PI3K phosphorylation. Recently, we demonstrated that PKC $\alpha$ inhibition by itself is insufficient to activate PI3K unless PKA is active. We suggest a dual role for PKA in the regulation of PI3K activity during bovine sperm capacitation. First, PKA mediates PI3K activation, and secondly, PKA mediates $\mathrm{PKC} \alpha$ and PP1 $\gamma 2$ degradation, which is necessary for PI3K activation.

A direct role for PKC $\alpha$ in the activation of the S/T phosphatase $\mathrm{PP} 2 \mathrm{~A}$, which results in PI3K inhibition through removal of PI3K phosphorylation, was recently shown in epithelial cells. ${ }^{80}$ The finding that PKC $\alpha$ and PP1 $\gamma 2$ are degraded during the capacitation process suggested the involvement of degradation system(s) which regulates the cellular levels of these proteins. The two major proteolytic pathways in eukaryotic cells are the ubiquitin/proteasome system and the lysosomal pathway. Since lysosomes do not exist in sperm cells, while proteasomes are present, it is likely that the ubiquitin/proteasome pathway is involved in the degradation of PKC $\alpha$ and/or PP $1 \gamma 2 .{ }^{81}$ Most recently, it was reported that proteasomal activity is important for human sperm capacitation, and that PKA activity regulates the chymotrypsin-like activity of the proteasome during capacitation. ${ }^{82}$ Another study revealed that PKA can positively regulate the proteasomal activity by phosphorylation of Rpt6, one of the six AAAATPases in the $19 S$ regulatory subunit of the proteasome. ${ }^{83}$ We therefore suggest a mechanism of cross-talk between PKC and PKA that regulates PI3K phosphorylation/activation. At the beginning of the capacitation process, $\mathrm{PKC} \alpha$ and $\mathrm{PP} 1 \gamma 2$ are active and present in high levels and inhibit (directly or indirectly) PI3K phosphorylation. ${ }^{76}$ With ongoing capacitation, PKA mediates PKC $\alpha$ and PP $1 \gamma 2$ degradation, the inhibition of PI3K by PKC $\alpha / \mathrm{PP} 1 \gamma 2$ is relaxed and PI3K phosphorylation/activation by PKA can occur.

\section{ACTIN POLYMERIZATION AND DEPOLYMERIZATION}

PI3K activation by direct phosphorylation of $\mathrm{p} 85$, the regulatory subunit, leads to actin polymerization. ${ }^{38,84,85}$ We have previously shown that actin polymerization occurs during sperm capacitation and that F-actin breakdown must take place to achieve the AR. ${ }^{86}$ It has been suggested that an increase in F-actin creates a network between the plasma and the outer acrosomal membranes, and the dispersion of Factin between the two membranes is needed to enable the AR. ${ }^{86-89}$

The presence of actin-binding proteins in mammalian sperm suggests that the assembly of G-actin to form F-actin, as well as the disassembly of F-actin are well-controlled events. ${ }^{90-92}$ Gelsolin severs assembled actin filaments, and caps the fast-growing plus end of free or newly severed filaments in response to $\mathrm{Ca}^{2+}$. Phosphoinositides bind gelsolin and release it from actin filament ends, exposing sites for actin assembly. ${ }^{93,94}$ We recently showed that gelsolin is inactive during capacitation, and is activated prior to the AR. ${ }^{70}$

The release of bound gelsolin from phosphatidylinositol 4,5bisphosphate $\left(\mathrm{PIP}_{2(4,5)}\right)$ by PBP10, a peptide containing the $\mathrm{PIP}_{2^{-}}$ binding domain of gelsolin, or by activation of PLC, which hydrolyzes $\mathrm{PIP}_{2}$, causes rapid $\mathrm{Ca}^{2+}$-dependent F-actin depolymerization as well as an enhanced $\mathrm{AR}^{70}$ The activation of PLC, which hydrolyzes $\mathrm{PIP}_{2(4,5)}$, releases the bound gelsolin and enables its activity of breaking down F-actin, resulting in the AR. Thus, PLC activity mediates Factin depolymerization at the end of capacitation, leading to the AR.

We have previously shown that epidermal growth factor receptor (EGFR) is involved in the $\mathrm{AR}^{95}$ and in actin polymerization during capacitation. $^{86,96}$

We also show that the EGFR is partially activated in sperm incubated under capacitation conditions and is fully activated by adding EGF at the end of the capacitation resulting in the occurance of the AR. ${ }^{97}$ In our recent study, we show that $\alpha 7$-nicotinic-acetyl-cholinereceptor $(\alpha 7 \mathrm{nAChR})$ is a potential sperm receptor that can be activated by the egg ZP to induce EGFR-mediated AR. ${ }^{98}$ It was also shown by others that EGFR is involved in boar sperm motility ${ }^{99}$ and was localized at higher extent to the acrosome region than to the postacrosome and the flagellum. ${ }^{98}$ Moreover, EGF signaling was shown to be an important pathway identified in high fertility sperm in a recent comprehensive proteomic analysis. ${ }^{100}$

Previous studies identified Src in human spermatozoa, and it appears to be involved in regulating sperm capacitation, calcium fluxes, tyrosine phosphorylation and the AR. ${ }^{35} \mathrm{Src}$ and gelsolin coimmunoprecipitate, and Src phosphorylates gelsolin on tyrosine-438 and 

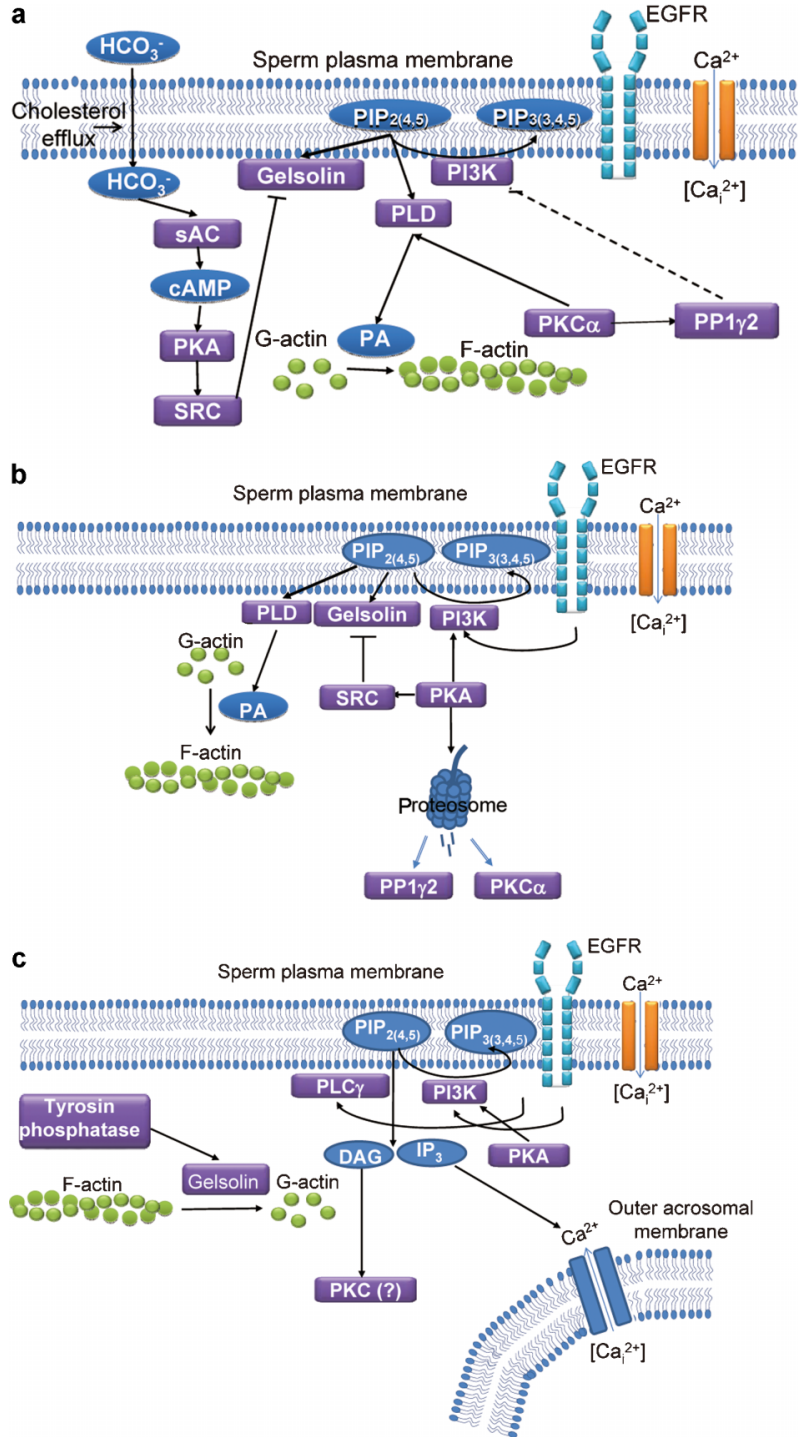

Figure 1 A model describing the involvement of various kinases in sperm capacitation and the AR. The model is composed of three steps: (a) Beginning of capacitation. (b) Ongoing capacitation. (c) The AR. (a) Beginning of capacitation. Activation of $\mathrm{NBC}$ and CatSper results in fast increase in intracellular $\mathrm{HCO}_{3}{ }^{-}$and $\mathrm{Ca}^{2+}$ resulting in SACY/PKA activation. Later on efflux of cholesterol from the sperm plasma membrane enhances further bicarbonate permeability into the cell resulting in further activation of SACY, CAMP production and PKA activation. PKA activation leads to Src-mediated gelsolin phosphorylation maintaing $\mathrm{PIP}_{2^{-}}$ bound gelsolin in an inactive state and thereby stabilizing the polymerized actin. At the beginning of capacitation process, PKC $\alpha$ is in its active state which leads to PP $1 \gamma 2$ phosphorylation/activation. PP $1 \gamma 2$ causes PI3K dephosphorylation/ inhibition. At this stage, the level of $\mathrm{PIP}_{2}$ increases, resulting in PLD activation which produces PA leading to actin polymerization. (b) Ongoing capacitation. PKA mediates proteasome dependent PKC $\alpha$ and PP1 $\gamma 2$ degradation, leading to $\mathrm{PI} 3 \mathrm{~K}$ phosphorylation/activation. During capacitation, $\mathrm{Ca}^{2+}$ concentration is elevated, EGFR is partially activated resulting in PI3K activation. At this stage, gelsolin still bound to $\mathrm{PIP}_{2}$ in an inactive state and thereby depolymerization of $\mathrm{F}$ actin is prevented. (c) The AR. Sperm binding to the egg ZP stimulates relatively high elevation of intracellular $\mathrm{Ca}^{2+}$ and EGFR is activated, leading to PLC $\gamma$ and PI3K activation. PI3K phosphorylation can also occur by PKA activation. PLC $\gamma$ hydrolyzes $\mathrm{PIP}_{2}$ resulting in DAG and $I \mathrm{P}_{3}$ production. DAG activates $\mathrm{PKC}$ and $I \mathrm{P}_{3}$ activates $\mathrm{Ca}^{2+}$ efflux from the acrosome. The decrease in $\mathrm{PIP}_{2}$ levels results in the release of gelsolin to the cytosol following by its dephosphrylation/activation by tyrosine phosphatases leading to $\mathrm{F}$-actin depolimerization and the occurrence of the AR. AR, acrosome reaction; CAMP, cyclic adenosine monophosphate;
DAG, diacylglycerol; EGFR, epidermal growth factor receptor; $\mathrm{NBC}, \mathrm{Na}^{+} /$ $\mathrm{HCO}_{3}{ }^{-}$cotransporter; PA, phosphatidic acid; PI3K, phosphatidyl-inositol-3kinase; PKA, protein kinase A; PKC, protein kinase C; PLC, phospholipase C; PLD, phospholipase D; SACY, soluble adenylyl cyclase; ZP, zona pellucida.

inhibits its activity. ${ }^{70}$ Actin polymerization is blocked by inhibiting the SFKs, suggesting that gelsolin is activated under these conditions.

We suggest that during capacitation, the intracellular $\mathrm{Ca}^{2+}$ concentration rises, leading to conformational changes in gelsolin and exposing its F-actin-binding site. As a result, gelsolin is activated and translocated to the head of the sperm. ${ }^{63}$ Nevertheless, the elevation of $\mathrm{PIP}_{2(4,5)}$ levels and gelsolin phosphorylation maintain gelsolin in an inactive state, allowing actin polymerization to occur. Prior to the AR, the intracellular $\mathrm{Ca}^{2+}$ concentration is further elevated: PLC is activated and hydrolyzes $\mathrm{PIP}_{2(4,5)}$ resulting in the release of gelsolin to the cytosol. The free gelsolin becomes activated as a result of elevated levels of $\mathrm{Ca}^{2+}$ and tyrosine dephosphorylation by tyrosine phosphatases, leading to F-actin dispersion and the $\mathrm{AR}^{70}$ This interpretation is consistent with the role of $\mathrm{PIP}_{2(4,5)}$ as a cofactor for PLD activation which mediates actin polymerization in capacitation. ${ }^{71,101}$

It has been shown in several cell types that PLD, the enzyme that hydrolyzes phosphatidylcholine to phosphatidic acid and choline, ${ }^{102}$ is involved in the regulation of the actin cytoskeleton. ${ }^{102-104}$ We showed elsewhere that PLD-dependent actin polymerization is a necessary step in the cascade leading to bull sperm capacitation. ${ }^{70,71}$ PLD as well as actin polymerization is also involved in regulating cell motility. ${ }^{103}$

In our recent study, we showed that the development of HAM in mouse sperm during capacitation depends upon actin polymerization. ${ }^{101}$ Moreover, we also showed that progressive sperm motility depends on PLD activity as well. ${ }^{101}$

In Figure 1, we suggest a model which unifies the different kinase cascades involved in sperm capacitation and the AR.

\section{CONCLUSIONS}

During the capacitation process, $\mathrm{PI} 3 \mathrm{~K}$ is phosphorylated/activated via a PKA-dependent cascade, and downregulated by PKC $\alpha$. PKC $\alpha$ is active at the beginning of capacitation, resulting in PI3K inactivation. During capacitation, PKC $\alpha$ as well as PP $1 \gamma 2$ is degraded by a PKAdependent mechanism, allowing the activation of PI3K. This activation of PKA leads to an increase in actin polymerization, an essential process for the development of hyperactivated motility, which is necessary for successful fertilization. Actin polymerization is mediated by $\mathrm{PIP}_{2}$ in two ways: first, $\mathrm{PIP}_{2}$ acts as a cofactor for PLD activation, and second, as a molecule that binds and inhibits actin-severing proteins such as gelsolin. Tyrosine phosphorylation of gelsolin during capacitation by SFK is also important for its inactivation. Prior to the AR, gelsolin is released from $\mathrm{PIP}_{2}$ and undergoes dephosphorylation/activation, resulting in fast F-actin depolymerization, leading to the AR.

\section{COMPETING FINANCIAL INTERESTS}

The authors declare no competing financial interest.

\section{ACKNOWLEDGMENTS}

Grants covering the research: Ihel Foundation to HB.

1 Florman HM, Ducibella T. Fertilization in mammals. In: Neill JD, editor. Physiology of Reproduction. San Diego, CA: Elsevier; 2006. p55-112.

2 Gadella BM, Visconti A. Regulation of capacitation. In: de Jonge CJ, Barratt C, editors The Sperm Cell. Cambridge: Cambridge University Press; 2006. p134-69. 
3 Austin CR. Observations on the penetration of the sperm into the mammalian egg. Aust J Sci Res B 1951; 4: 581-96.

4 Chang MC. Fertilization capacity of spermatozoa deposited in fallopian tubes. Nature 1951; 168: 697-8.

5 Yanagimachi R. Mammalian fertilization. In: Knobil E, Neil JD, editors. The Physiology of Reproduction. New York: Raven Press; 1994. p189-317.

6 Roldan ER, Shi QX. Sperm phospholipases and acrosomal exocytosis. Front Biosci 2007; 12: 89-104.

7 Florman HM, Jungnickel MK, Sutton KA. Regulating the acrosome reaction. Int J Dev Biol 2008; 52: 503-10.

8 Breitbart $\mathrm{H}$. Signaling pathways in sperm capacitation and acrosome reaction. Cell Mol Biol 2003; 49: 321-7.

9 Hernandez-Gonzalez EO, Sosnik J, Edwards J, Acevedo JJ, Mendoza-Lujambio I et al. Sodium and epithelial sodium channels participate in the regulation of the capacitation-associated hyperpolarization in mouse sperm. J Biol Chem 2006; 281: 5623-33.

10 Arcelay E, Salicioni AM, Wertheimer E, Visconti PE. Identification of proteins undergoing tyrosine phosphorylation during mouse sperm capacitation. Int J Dev Biol 2008; 52: 463-72.

11 Visconti PE. Understanding the molecular basis of sperm capacitation through kinase design. Proc Natl Acad Sci USA 2009; 106: 667-8.

12 Baldi E, Luconi M, Bonaccorsi L, Muratori M, Forti G. Intracellular events and signaling pathways involved in sperm acquisition of fertilizing capacity and acrosome reaction. Front Biosci 2000; 5: E110-23.

13 Salicioni AM, Platt MD, Wertheimer EV, Arcelay E, Allaire A et al. Signalling pathways involved in sperm capacitation. Soc Reprod Fertil Supp/ 2007; 65: 245-59.

14 Hunter T. Signaling-2000 and beyond. Cell 2000; 100: 113-27.

15 Pawson T. Specificity in signal transduction: from phosphotyrosine-SH2 domain interactions to complex cellular systems. Cell 2004; 116: 191-203.

16 Ficarro S, Chertihin O, Westbrook VA, White F, Jayes F et al. Phosphoproteome analysis of capacitated human sperm. Evidence of tyrosine phosphorylation of a kinase-anchoring protein 3 and valosin-containing protein/p97 during capacitation. J Biol Chem 2003; 278: 11579-89.

17 Roy SC, Atreja SK. Tyrosine phosphorylation of a 38-kDa capacitation-associated buffalo (Bubalus bubalis) sperm protein is induced by L-arginine and regulated through a cAMP/PKA-independent pathway. Int J Androl 2008; 31: 12-24.

18 Roy SC, Atreja SK. Effect of reactive oxygen species on capacitation and associated protein tyrosine phosphorylation in buffalo (Bubalus bubalis) spermatozoa. Anim Reprod Sci 2008; 107: 68-84.

19 Visconti PE, Bailey JL, Moore GD, Pan D, Olds-Clarke P et al. Capacitation of mouse spermatozoa. I. Correlation between the capacitation state and protein tyrosine phosphorylation. Development 1995; 121: 1129-37.

20 Visconti PE, Moore GD, Bailey JL, Leclerc P, Connors SA et al. Capacitation of mouse spermatozoa. II. Protein tyrosine phosphorylation and capacitation are regulated by a cAMP-dependent pathway. Development 1995; 121: 1139-50.

21 Signorelli J, Diaz ES, Morales P. Kinases, phosphatases and proteases during sperm capacitation. Cell Tissue Res; e-pub ahead of print 20 March 2012; doi:10.1007/ s00441-012-1370-3.

22 Jagan Mohanarao G, Atreja SK. Identification of capacitation associated tyrosine phosphoproteins in buffalo (Bubalus bubalis) and cattle spermatozoa. Anim Reprod Sci 2011; 123: 40-7.

23 Naaby-Hansen S, Mandal A, Wolkowicz MJ, Sen B, Westbrook VA et al. CABYR, a novel calcium-binding tyrosine phosphorylation-regulated fibrous sheath protein involved in capacitation. Dev Biol 2002; 242: 236-54.

24 Luconi M, Barni T, Vannelli GB, Krausz C, Marra F et al. Extracellular signal-regulated kinases modulate capacitation of human spermatozoa. Biol Reprod 1998; 58: 1476 89.

25 Luconi M, Krausz C, Barni T, Vannelli GB, Forti G et al. Progesterone stimulates p42 extracellular signal-regulated kinase (p42erk) in human spermatozoa. Mol Hum Reprod 1998; 4: 251-8.

26 Muratori M, Marchiani S, Tamburrino L, Forti G, Luconi M et al. Markers of human sperm functions in the ICSI era. Front Biosci 2011; 16: 1344-63.

27 Demarco IA, Espinosa F, Edwards J, Sosnik J, de la Vega-Beltran JL et al. Involvement of a $\mathrm{Na}^{+} / \mathrm{HCO}^{-3}$ cotransporter in mouse sperm capacitation. J Biol Chem 2003; 278: 7001-9.

28 Gadella BM, Harrison RA. The capacitating agent bicarbonate induces protein kinase A-dependent changes in phospholipid transbilayer behavior in the sperm plasma membrane. Development 2000; 127: 2407-20.

29 Wennemuth G, Carlson AE, Harper AJ, Babcock DF. Bicarbonate actions on flagellar and $\mathrm{Ca}^{2+}$-channel responses: initial events in sperm activation. Development 2003; 130: 1317-26.

30 Okamura N, Tajima Y, Soejima A, Masuda H, Sugita Y. Sodium bicarbonate in seminal plasma stimulates the motility of mammalian spermatozoa through direct activation of adenylate cyclase. J Biol Chem 1985; 260: 9699-705.

31 Holt WV, Harrison RA. Bicarbonate stimulation of boar sperm motility via a protein kinase A-dependent pathway: between-cell and between-ejaculate differences are not due to deficiencies in protein kinase A activation. J Androl 2002; 23: 557-65.

32 Bajpai M, Doncel GF. Involvement of tyrosine kinase and CAMP-dependent kinase cross-talk in the regulation of human sperm motility. Reproduction 2003; 126 : 183-95.

33 Luconi M, Porazzi I, Ferruzzi P, Marchiani S, Forti G et al. Tyrosine phosphorylation of the a kinase anchoring protein 3 (AKAP3) and soluble adenylate cyclase are involved in the increase of human sperm motility by bicarbonate. Biol Reprod 2005; 72: 22 32.

34 Visconti PE, Krapf D, de la Vega-Beltran JL, Acevedo JJ, Darszon A. Ion channels, phosphorylation and mammalian sperm capacitation. Asian J Androl2011; 13: 395405.

35 Varano G, Lombardi A, Cantini G, Forti G, Baldi E et al. Src activation triggers capacitation and acrosome reaction but not motility in human spermatozoa. Hum Reprod 2008; 23: 2652-62.

36 Lawson C, Goupil S, Leclerc P. Increased activity of the human sperm tyrosine kinase SRC by the cAMP-dependent pathway in the presence of calcium. Biol Reprod 2008; 79: 657-66.

37 Mitchell LA, Nixon B, Baker MA, Aitken RJ. Investigation of the role of SRC in capacitation-associated tyrosine phosphorylation of human spermatozoa. Mol Hum Reprod 2008; 14: 235-43.

38 Etkovitz N, Rubinstein S, Daniel L, Breitbart H. Role of PI3-kinase and PI4-kinase in actin polymerization during bovine sperm capacitation. Biol Reprod 2007; 77: 26373.

39 Becker W, Kentrup H, Klumpp S, Schultz JE, Joost HG. Molecular cloning of a protein serine/threonine phosphatase containing a putative regulatory tetratricopeptide repeat domain. J Biol Chem 1994; 269: 22586-92.

40 Lalancette $\mathrm{C}$, Faure RL, Leclerc $\mathrm{P}$. Identification of the proteins present in the bull sperm cytosolic fraction enriched in tyrosine kinase activity: a proteomic approach. Proteomics 2006; 6: 4523-40.

41 Baker MA, Hetherington L, Aitken RJ. Identification of SRC as a key PKA-stimulated tyrosine kinase involved in the capacitation-associated hyperactivation of murine spermatozoa. J Cell Sci 2006; 119: 3182-92.

42 Leclerc $P$, de Lamirande E, Gagnon C. Cyclic adenosine 3',5'monophosphatedependent regulation of protein tyrosine phosphorylation in relation to human sperm capacitation and motility. Biol Reprod 1996; 55: 684-92.

43 Liu DY, Clarke GN, Baker HW. Tyrosine phosphorylation on capacitated human sperm tail detected by immunofluorescence correlates strongly with sperm-zona pellucida (ZP) binding but not with the ZP-induced acrosome reaction. Hum Reprod 2006; 21: 1002-8.

44 Buffone MG, Verstraeten SV, Calamera JC, Doncel GF. High cholesterol content and decreased membrane fluidity in human spermatozoa are associated with protein tyrosine phosphorylation and functional deficiencies. J Androl 2009; 30: 552-8.

45 Nolan MA, Babcock DF, Wennemuth G, Brown W, Burton KA et al. Sperm-specific protein kinase A catalytic subunit Calpha2 orchestrates CAMP signaling for male fertility. Proc Natl Acad Sci USA 2004; 101: 13483-8.

46 Hess KC, Jones BH, Marquez B, Chen Y, Ord TS et al. The 'soluble' adenylyl cyclase in sperm mediates multiple signaling events required for fertilization. Dev Cel/2005; 9: 249-59.

47 Esposito G, Jaiswal BS, Xie F, Krajnc-Franken MA, Robben TJ et al. Mice deficient for soluble adenylyl cyclase are infertile because of a severe sperm-motility defect. Proc Natl Acad Sci USA 2004; 101: 2993-8.

48 Carlson AE, Hille B, Babcock DF. External $\mathrm{Ca}^{2+}$ acts upstream of adenylyl cyclase SACY in the bicarbonate signaled activation of sperm motility. Dev Biol 2007; 312: 183-92.

49 Shahar S, Wiser A, Ickowicz D, Lubart R, Shulman A et al. Light-mediated activation reveals a key role for protein kinase $A$ and sarcoma protein kinase in the development of sperm hyper-activated motility. Hum Reprod 2011; 26: 2274-82.

50 de Lamirande E, Gagnon C. Human sperm hyperactivation in whole semen and its association with low superoxide scavenging capacity in seminal plasma. Fertil Steril 1993; 59: 1291-5.

51 Goodson SG, Zhang Z, Tsuruta JK, Wang W, O'Brien DA. Classification of mouse sperm motility patterns using an automated multiclass support vector machines model. Biol Reprod 2011; 84: 1207-15.

52 Mortimer ST, Mortimer D. Kinematics of human spermatozoa incubated under capacitating conditions. J Androl 1990; 11: 195-203.

53 Demott RP, Suarez SS. Hyperactivated sperm progress in the mouse oviduct. Biol Reprod 1992; 46: 779-85.

54 Katz DF, Yanagimachi R. Movement characteristics of hamster spermatozoa within the oviduct. Biol Reprod 1980; 22: 759-64.

55 Suarez SS, Vincenti L, Ceglia MW. Hyperactivated motility induced in mouse sperm by calcium ionophore A23187 is reversible. J Exp Zool 1987; 244: 331-6.

56 Ho HC, Suarez SS. Hyperactivation of mammalian spermatozoa: function and regulation. Reproduction 2001; 122: 519-26.

57 Stauss CR, Votta TJ, Suarez SS. Sperm motility hyperactivation facilitates penetration of the hamster zona pellucida. Biol Reprod 1995; 53: 1280-5.

58 Amieux PS, McKnight GS. The essential role of RI alpha in the maintenance of regulated PKA activity. Ann NY Acad Sci 2002; 968: 75-95.

59 Rotem R, Paz GF, Homonnai ZT, Kalina M, Naor Z. Protein kinase C is present in human sperm: possible role in flagellar motility. Proc Natl Acad Sci USA 1990; 87: 7305-8.

60 Roldan ERS, Harrison RAP. Absence of active protein kinase $C$ in ram spermatozoa. Biochem Biophys Res Commun 1988; 155: 901-6.

61 Breitbart H, Lax Y, Rotem R, Naor Z. Role of protein kinase $\mathrm{C}$ in the acrosome reaction of mammalian spermatozoa. Biochem J 1992; 281: 473-6.

62 Naor Z, Breitbart H. Protein kinase C and mammalian spermatozoa acrosome reaction. TEM 1997; 8: 337-42.

63 Kalive M, Faust JJ, Koeneman BA, Capco DG. Involvement of the PKC family in regulation of early development. Mol Reprod Dev 2010; 77: 95-104. 
64 Liu XF, Xie X, Miki T. Inhibition of protein kinase C zeta blocks the attachment of stable microtubules to kinetochores leading to abnormal chromosome alignment. Cell Signal 2006; 18: 2314-23.

65 Newton AC. Protein kinase C: structure, function and regulation. J Biol Chem 1995; 270: 28495-8.

66 Nishizuka Y. Intracellular signaling by hydrolysis of phospholipids and activation of protein kinase C. Science 1992; 258: 607-14.

67 Yanagimachi R, Usui N. Calcium dependence of the acrosome reaction and activation of the guinea pig spermatozoa. Exp Cell Res 1974; 89: 161-74.

68 Florman HM, Tombes RM, First NL, Babcock DF. An adhesion-associated agonist from the zona pellucida activates $\mathrm{G}$ protein-promoted elevations of internal $\mathrm{Ca}^{2+}$ and $\mathrm{pH}$ that mediate mammalian sperm acrosomal exocytosis. Dev Biol 1989; 35: 133-49.

69 Rotem R, Paz GF, Homonnai ZT, Kalina M, Lax Y et al. $\mathrm{Ca}^{2+}$-independent induction of acrosome reaction by protein kinase $\mathrm{C}$ in human sperm. Endocrinology 1992; 131 2235-43

70 Finkelstein $\mathrm{M}$, Etkovitz $\mathrm{N}$, Breitbart $\mathrm{H}$. Role and regulation of sperm gelsolin prior to fertilization. J Biol Chem 2010; 285: 39702-9.

71 Cohen G, Rubinstein S, Gur Y, Breitbart H. Crosstalk between protein kinase A and C regulates phospholipase $\mathrm{D}$ and $\mathrm{F}$-actin formation during sperm capacitation. Dev Biol 2004; 267: 230-41.

72 Spungin B, Breitbart $\mathrm{H}$. Calcium mobilization and influx during sperm exocytosis J Cell Sci 1996; 109: 1947-55.

73 O'Toole CM, Roldan ER, Hampton P, Fraser LR. A role for diacylglycerol in human sperm acrosomal exocytosis. Mol Hum Reprod 1996; 2: 317-26.

74 Rotem R, Paz GF, Homonnai ZT, Kalina M, Naor Z. Further studies on the involvement of protein kinase C in human sperm flagellar motility. Endocrinology 1990; 127 2571-7.

75 Lax Y, Rubinstein S, Breitbart H. Subcellular distribution of protein kinase $\mathrm{C}$ alpha and betal in bovine spermatozoa, and their regulation by calcium and phorbol esters. Biol Reprod 1997; 56: 454-9.

76 Rotman T, Etkovitz N, Spiegel A, Rubinstein S, Breitbart H. Protein kinase A and protein kinase C(alpha)/PPP1CC2 play opposing roles in the regulation of phosphatidylinositol 3-kinase activation in bovine sperm. Reproduction 2010; 140 43-56.

77 Cantley LC. The phosphoinositide 3-kinase pathway. Science 2002; 296: 1655-7.

78 Fisher HM, Brewis IA, Barratt CL, Cooke ID, Moore HD. Phosphoinositide 3-kinase is involved in the induction of the human sperm acrosome reaction downstream of tyrosine phosphorylation. Mol Hum Reprod 1998; 4: 849-55.

79 Jungnickel MK, Sutton KA, Wang Y, Florman HM. Phosphoinositide-dependent pathways in mouse sperm are regulated by egg ZP3 and drive the acrosome reaction. Dev Biol 2007; 304: 116-26.

80 Guan L, Song K, Pysz MA, Curry KJ, Hizli AA et al. Protein kinase C-mediated downregulation of cyclin $\mathrm{D} 1$ involves activation of the translational repressor $4 \mathrm{E}-\mathrm{BP} 1$ via a phosphoinositide 3-kinase/Akt-independent, protein phosphatase 2A-dependent mechanism in intestinal epithelial cells. J Biol Chem 2007; 282: 14213-25.

81 Moreno RD, Alvarado CP. The mammalian acrosome as a secretory lysosome: new and old evidence. Mol Reprod Dev 2006; 73: 1430-4.

82 Kong M, Diaz ES, Morales P. Participation of the human sperm proteasome in the capacitation process and its regulation by protein kinase $\mathrm{A}$ and tyrosine kinase. Biol Reprod 2009; 80: 1026-35.

83 Zhang $\mathrm{F}, \mathrm{Hu}$ Y, Huang $\mathrm{P}$, Toleman CA, Paterson AJ et al. Proteasome function is regulated by cyclic AMP-dependent protein kinase through phosphorylation of Rpt6. J Biol Chem 2007; 282: 22460-71

84 de Gregorio G, Coppa A, Cosentino C, Ucci S, Messina S et al. The p85 regulatory subunit of PI3K mediates TSH-CAMP-PKA growth and survival signals. Oncogene 2007; 26: 2039-47.
85 Cosentino C, di Domenico M, Porcellini A, Cuozzo C, de Gregorio G et al p85 regulatory subunit of $\mathrm{PI} 3 \mathrm{~K}$ mediates CAMP-PKA and estrogens biological effects on growth and survival. Oncogene 2007; 26: 2095-103.

86 Brener E, Rubinstein S, Cohen G, Shternall K, Rivlin J et al. Remodeling of the actin cytoskeleton during mammalian sperm capacitation and acrosome reaction. Biol Reprod 2003; 68: 837-45

87 Arnoult C, Kazam IG, Visconti PE, Kopf GS, Villaz M et al. Control of the low voltageactivated calcium channel of mouse sperm by egg ZP3 and by membrane hyperpolarization during capacitation. Proc Natl Acad Sci USA 1999; 96: 6757-62.

88 Breitbart H, Cohen G, Rubinstein S. Role of actin cytoskeleton in mammalian sperm capacitation and the acrosome reaction. Reproduction 2005; 129: 263-8.

89 Spungin B, Margalit I, Breitbart $\mathrm{H}$. Sperm exocytosis reconstructed in a cell-free system: evidence for the involvement of phospholipase $C$ and actin filaments in membrane fusion. J Cell Sci 1995; 108(Pt 6): 2525-35.

90 Tanaka $\mathrm{H}$, Yoshimura $\mathrm{Y}$, Nishina $\mathrm{Y}$, Nozaki M, Nojima $\mathrm{H}$ et al. Isolation and characterization of cDNA clones specifically expressed in testicular germ cells. FEBS Lett 1994; 355: 4-10.

91 von Bulow M, Heid $\mathrm{H}$, Hess $\mathrm{H}$, Franke WW. Molecular nature of calicin, a major basic protein of the mammalian sperm head cytoskeleton. Exp Cell Res 1995; 219: 40713

92 von Bulow M, Rackwitz HR, Zimbelmann R, Franke WW. CP beta3, a novel isoform of an actin-binding protein, is a component of the cytoskeletal calyx of the mammalian sperm head. Exp Cell Res 1997; 233: 216-24.

93 Janmey PA, lida K, Yin HL, Stossel TP. Polyphosphoinositide micelles and polyphosphoinositide-containing vesicles dissociate endogenous gelsolin-actin complexes and promote actin assembly from the fast-growing end of actin filaments blocked by gelsolin. J Biol Chem 1987; 262: 12228-36.

94 Gremm D, Wegner A. Gelsolin as a calcium-regulated actin filament-capping protein. Eur J Biochem 2000; 267: 4339-45.

95 Lax $Y$, Rubinstein S, Breitbart H. Epidermal growth factor induces acrosomal exocytosis in bovine sperm. FEBS Lett 1994; 339: 234-8.

96 Breitbart $\mathrm{H}$, Etkovitz $\mathrm{N}$. Role and regulation of EGFR in actin remodeling in sperm capacitation and the acrosome reaction. Asian J Androl 2011; 13: 106-10.

97 Etkovitz N, Tirosh Y, Chazan R, Jaldety Y, Daniel L et al. Bovine sperm acrosome reaction induced by $\mathrm{G}$ protein-coupled receptor agonists is mediated by epidermal growth factor receptor transactivation. Dev Biol 2009; 334: 447-57.

98 Jaldety Y, Glick Y, Orr-Urtreger A, Iscowicz D, Gerber D et al. Sperm EGFR mediates alpha7 AChR activation to promote fertilization. J Biol Chem 2012; 287: 22328-40.

99 Oliva-Hernandez J, Perez-Gutierrez JF. Localization of the epidermal growth facto (EGF) in the epididymis and accessory genital glands of the boar and functional effects on spermatozoa. Theriogenology 2008; 70: 1159-69.

100 Peddinti D, Nanduri B, Kaya A, Feugang JM, Burgess SC et al. Comprehensive proteomic analysis of bovine spermatozoa of varying fertility rates and identification of biomarkers associated with fertility. BMC Syst Biol 2008; 2: 19.

101 Itach SB, Finklestein M, Etkovitz N, Breitbart H. Hyper-activated motility in sperm capacitation is mediated by phospholipase D-dependent actin polymerization. Dev Biol 2012; 362: 154-61.

$102 \mathrm{Kam}$ Y, Exton JH. Phospholipase D activity is required for actin stress fiber formation in fibroblasts. Mol Cell Biol 2001; 21: 4055-66.

103 Kusner DJ, Barton JA, Wen KK, Wang X, Rubenstein PA et al. Regulation of phospholipase $\mathrm{D}$ activity by actin. Actin exerts bidirectional modulation of Mammalian phospholipase $D$ activity in a polymerization-dependent, isoformspecific manner. J Biol Chem 2002; 277: 50683-92.

104 Cross MJ, Roberts S, Ridley AJ, Hodgkin MN, Stewart A et al. Stimulation of actin stress fibre formation mediated by activation of phospholipase D.Curr Biol 1996; 6: 588-97. 